\title{
Commentary \\ Post-injury multiple organ failure and late outcome. Is it just an association? \\ Massimo Antonelli ${ }^{1}$ and Anselmo Caricato ${ }^{1}$
}

${ }^{1}$ Institute of Anesthesia and Intensive Care, Catholic University School of Medicine, Rome, Italy

Corresponding author: Massimo Antonelli, m.antonelli@rm.unicatt.it

Published: 29 October 2007

This article is online at http://ccforum.com/content/11/5/166

(c) 2007 BioMed Central Ltd

See related research by Ulvik et al., http://ccforum.com/content/11/5/R95
Critical Care 2007, 11:166 (doi:10.1186/cc6132)

\begin{abstract}
Multiple organ failure (MOF) is associated with a high rate of mortality in trauma patients. Several studies focused on long-term outcome in these patients, and showed that MOF is related to both in-hospital and late mortality and functional status. Exact mechanism of sequelae in MOF is still unclear. The distinction between early and late MOF probably helps to separate two different clinical conditions and find a stronger relationship with outcome.
\end{abstract}

Detailed information about the prognosis of trauma patients is crucial to improve survival in the intensive care unit (ICU). Indeed, most of the studies have been focused on ICU or inhospital mortality, and long-term outcome remains largely unknown. In addition, follow-up is often difficult to achieve, and several missing data may occur. If the first objective of intensive care is survival, the ultimate goal is the quality of patients' survival. Several authors worked on this topic in the intensive care setting, and in the current issue of the journal, Ulvik et al. [1] looked at some of these problems, adding an important contribution to the outcome definition in trauma patients. However, measuring the quality of life means translating a personal perception into numbers, with results not always being satisfactory. Recently, a consensus conference on quality of life recommended Glasgow Outcome Scale (GOS) and SF-36 as generic tools in trauma patients, together with condition-specific instruments to better reflect the long-term problems of these patients [2].

In the study by Ulvik et al., [1] two to seven years after the trauma, they investigated GOS and an index related to physical functional status, Karnofsky's index, that takes account of the presence of symptoms, the working ability, the physical activity, and self-care. Their data show that two years after the injury only half of the patients had made a full recovery. In particular, about $90 \%$ of the survivors had a GOS between four and five, and a Karnofsky's index above 60 , which corresponds to being able to live independently without assistance. Survival is low, but long-term outcome of survivors is not bad. The point is that the mortality rate increases over time stabilizing only 24-36 months after the injurious event. The patients dying after hospital discharge had multiple organ failure (MOF) during their stay in the ICU. In other words, MOF affects mortality not only in the first phase after trauma, but even after discharge. Ulvik and collaborators do not comment on this finding.

In their initial study on MOF, Fry et al. identified acute renal failure as the best indicator predicting mortality [3]. Moreno et al. observed a mortality rate after discharge of between $20 \%$ and $30 \%$ in general ICU patients that experienced MOF [4]. They found that neurologic and renal failures were mainly associated with late mortality. In trauma, co-morbidities are less significant determinants of the outcome. Is MOF simply associated with the severity of trauma or is it just the major cause of disability and death?

The current pathophysiologic model of MOF focuses on uncontrolled systemic hyperinflammation as a unifying concept following a variety of insults [5]. Particularly in trauma, two different kinds of organ failure have been described with different timing. Early MOF develops within 48-72 hours from trauma, mostly reflecting the host response to injury. This MOF is generally not sustained by infectious complication and sepsis. Multiple organ failures occurring lately after trauma are associated with the length of the resuscitation, the requirement of blood transfusion, and in particular with pneumonia and sepsis. This "bimodal" presentation might be the clinical expression of the postinjury hyperinflammatory response. Early MOF may progress 
to late MOF only if further inflammatory stimuli precipitated the uncontrolled inflammatory response [6]. Is late or early MOF associated with late mortality? The study by Ulvik and colleagues does not answer this question, but the point is crucial. Is it the efficacy of the resuscitation, or the treatment of sepsis that affects long-term survival? If sepsis is the key, late outcome in trauma might be an effect of septic complications.

Ulvik adds further data in favour of sequential organ failure assessment (SOFA) in trauma patients. SOFA was initially presented for assessing morbidity in septic patients, but has been validated also in trauma and in general ICU patients $[7,8]$. Recently it has been shown that the admission SOFA score, SOFA Max, and the changes in SOFA over the first 48 hours are correlated with mortality [9]. Ulvik shows that measuring SOFA score on admission and SOFA max may categorise trauma patients, enabling the identification of patients who, developing MOF, are at major risk of poor longterm survival and impaired functional status. Is this a suggestion for a standardisation of scoring MOF in trauma? This question remains unanswered and needs further investigation. The Ulvik paper adds a further step to the knowledge of long-term outcome in trauma patients. MOF appears to be associated with poor late prognosis, but we still don't know why. A better comprehension of the causes of long term disability and death is crucial for a further improvement of care.

\section{Competing interests}

The authors declare that they have no competing interests.

\section{References}

1. Ulvik $A$, Kvåle $R$, Wentzel-Larsen $T$, Flaatten $\mathrm{H}$ : Multiple organ failure after trauma affects even long-term survival and functional status. Crit Care 2007, 11:R95.

2. Neugebeauer $E$, Bouillon $B$, Bullinger $H$, Wood-Dauphinée $S$ : Quality of life after multiple trauma - summary and recommendations of the consensus conference. Restor Neurol Neurosci 2002, 20:161-167.

3. Fry DE, Pearlstein L, Fulton RL, Polk HC Jr: Multiple system organ failure. The role of uncontrolled infection. Arch Surg 1980, 115:136-140.

4. Moreno R, Miranda DR, Matos R, Fevereiro T: Mortality after discharge from intensive care: the impact of organ system failure and nursing workload use at discharge. Intensive Care Med 2001, 27:999-1004.

5. Keel M, Trentz O: Pathophysiology of polytrauma. Injury 2005, 36:691-709.

6. Ciesla DJ, Moore EE, Johnson JL, Cothren CC, Banerjee A, Burch $\mathrm{JH}$, Sauaia A: Decreased progression of postinjury lung dysfunction to the acute respiratory distress syndrome and multiple organ failure. Surgery 2006, 140:640-648.

7. Vincent JL, De Mendonca A, Cantraine F, Moreno R, Takala J, Suter PH, Sprung CL, Colardyn F, Blecher S: Use of the SOFA score to assess the incidence of organ dysfunction/failure in intensive care units: results of a multicentric, prospective study. Crit Care Med 1998, 26:1793-1800.

8. Antonelli M, Moreno R, Vincent JL, Sprung CL, Mendoça A, Passariello M, Riccioni M, Osborn J, SOFA Group: Application of SOFA score to trauma patients. Intensive Care Med 1999, 25:389-394.

9. Ferreira FL, Bota DP, Bross A, Mélot C, Vincent JL: Serial evaluation of SOFA score to predict outcome in critically ill patients. JAMA 2001, 286:1754-1758. 